\title{
The relationship between chair dimensions and musculoskeletal disorders among female students in one academic branch
}

\author{
Shariati $\mathrm{M}, \mathrm{MSc}^{1 *}$, Naderi $\mathrm{A}, \mathrm{PhD}^{2}$ \\ 1- Faculty Member, Dept. of Physical Education and Sport Sciences, Ahvaz Branch, Islamic Azad University, Ahvaz, Iran. \\ 2- Assistant Prof., Dept. of Physical Education and Sport Sciences, Izeh Branch, Islamic Azad University, Izeh, Iran.
}

\begin{abstract}
Received: October 2016, Accepted: December 2016

Background: Individuals, who spend most of their time sitting, are at 30\% more risk of suffering from lumbar disc than other people. One of the causes of pain in the lumbar region is musculoskeletal disorders (MSDs). MSDs are the most common and most costly injuries in occupational, administrative, and academic environments. Therefore, the aim of this study was to investigate the relationship between chair dimensions and the prevalence of MSDs in female students.

Materials and Methods: This descriptive-analytic and cross-sectional study was conducted on 101 female students of Ahvaz Branch, Islamic Azad University, Iran. Dimensions of chairs (width and length of chair seat, backrest length, and etc.) were measured using a tape measure and goniometer. Lordosis and kyphosis were evaluated using a Gravity line. Data were analyzed using chi-square test. All $p$ values of less than 0.05 were considered significant.

Results: The subjects' mean age was 27.12 years and $50 \%$ of the subjects had normal BMI. There was no significant relationship between ergonomic dimensions of chairs and kyphosis abnormality (P $<0.05)$. There was a significant relationship between lordosis abnormality and height of backrest $(\mathrm{P}=$ $0.04)$, seat to ground height $(\mathrm{P}=0.04)$, seat width $(\mathrm{P}=0.02)$, height of armrest $(\mathrm{P}=0.04)$, and armrest to seat height $(\mathrm{P}=0.04)$.

Conclusions: According to the results, the dimensions of chairs that were used in the university were not favorable. This could lead to the presentation of some MSDs. It is recommended that the anthropometric dimensions of the consumer society be considered before the purchasing of chairs.
\end{abstract}

Keywords: Ergonomics, Musculoskeletal Diseases, Furniture, Student

\section{Introduction}

Musculoskeletal disorders (MSDs) are the most common and most costly occupational injuries, because they account for a third of work-related injuries every year $(1,2)$. The economic losses caused by these disorders affect individuals, organizations, and the society (3). It is estimated that direct and indirect costs of MSDs account for about 1\% of the GDP of industrialized countries (4). MSDs are a global hidden epidemic (5). There is close relationship between MSDs and improper use of body mechanics. Factors such as bending and sitting are among the most important causes (6). Possible risk factors of MSDs include ergonomic pressure, BMI, sex, and disease $(7,8)$. The results of several studies suggest that women are at greater risk of MSDs than men (9-11). Bad posture due to use of inappropriate equipment at schools is among the most important risk factors of MSDs (12). Failure to observe ergonomic principles in the workplace can lead to higher incidence of spinal disorders $(13,14)$. Back pain is one of the most common disorders and $60 \%$ to $80 \%$ of women experience it throughout their lives (1). Lumbar disorders are the most important causes of absenteeism in the workplace (15). Postural abnormalities

\footnotetext{
* Corresponding author: Marina Shariati, Dept. of Physical Education and Sport Sciences, Ahvaz Branch, Islamic Azad University, Ahvaz, Iran. E-mail: Marina.shariati@yahoo.com
} 
are adverse changes that deform skeletal structure of the body's natural posture stature (16). If these abnormalities are not recognized and treated early, they will have adverse effects on the physiological function of the body such as kyphosis effect on the respiratory tract (17) or psychological and social consequences such as the relationship of kyphosis with depression (18). Natural spinal curves include both lordosis and kyphosis. There are four types of curves in the natural spine (cervical and lumbar lordosis, thoracic, and sacrum kyphosis) in order to preserve balance, flexibility, absorption, and pressure distribution. There are abnormalities such as scoliosis, kyphosis, and lordosis in the abnormal spine (19). The spine may change during life due to illness or wrong habits. Any changes in the spine lead to postural loss and body imbalance (20). Posture is defined as a combination of the position of joints relative to each other at one time. Each joint position will affect other joints' positions. Correct posture is when the lowest pressure is placed on joints and muscle activity is minimal. Postures that put pressure on joints are commonly known as poor posture (21).Ergonomy is the adaptation of the human workplace and life environment with anthropometric indices. Life tools and equipment can be designed so that their longterm use will not result in MSDs or malformations (22). The human body takes different states during hours of the day; some of these states lead to lesions and abnormalities over long-term repetitions (23). Non-compliance of equipment that are used continually with ergonomic standards and mismatch between the anthropometric characteristics of users can lead to structural and physiological disorders (24). Sadeqzadeh studied the correlation between physical dimensions of 52 students of 18-26 years of age and dimensions of available chairs in their faculty. Studies on anthropometric variables have indicated that there are differences between men and women in terms of shoulder width, seatback width, hip-popliteal length, and seat depth (25). Kalamklay et al. evaluated the anthropometric characteristics of 300 girls and boys of 18-25 years of age. The results indicated that there were significant differences between the two groups in terms of weight, structure, and physical dimensions and the differences had not been considered in designing school equipment (26). Students spend much of their time at the university (27); paying attention to comfortable and suitable furniture seems necessary for the maintaining their health and raising the education quality (28). Since the anthropometric data of men are used primarily in designing workstations, these stations are deemed inappropriate for women from the ergonomic point of view (29). Therefore, the ergonomic dimensions of chairs used in training centers are designed based on anthropometric characteristics of men, and using inappropriate desks and chairs may cause MSDs (29). Thus, this study aimed to determine the relationship between chair dimensions and MSDs among female students.

\section{Material and Methods}

This descriptive-analytic and cross-sectional study was conducted among female students of Islamic Azad University, Ahvaz Branch, Iran, in the fall of 2014. After survey announcement among 1,500 eligible female students (during 6 semesters), a total of 250 students referred, and finally, 101 individuals accepted to continue until the end of the study. The inclusion criteria included passing at least 3 years of study at the university, and lack of orthopedic problems, spine surgery, pain in the lumbar region, and neurological problems. All students were informed of the research process before measurement and completed the consent form. Information about all participants, including age, height (using tape meter), weight (using weigh scale), number of study years at the universities, were collected using a specific checklist that was prepared by the researcher. Presence or absence of kyphosis and lordosis abnormalities was determined using a Gravity line based on the New York organizational chart (30). All 
measurements were performed at 8 to 9 a.m. during one month. Ergonomic dimensions of chairs were measured based on figure 1, including chair seat height, chair seat length, chair seat width, chair backrest height, armrest to ground height, chair height, seat to ground height, and angle of chair backrest and seat (31). The researcher measured the dimensions of the 4 chair models used in classrooms in
Islamic Azad University, Ahvaz Branch. Kolmogorov-Smirnov test was used in the study in order to determine data normality, and chi-square test was used in order to test hypotheses. Data were analyzed in SPSS software (version 20, SPSS Inc., Chicago, IL, USA). The significance level of this study was determined as $\alpha=0.05$.

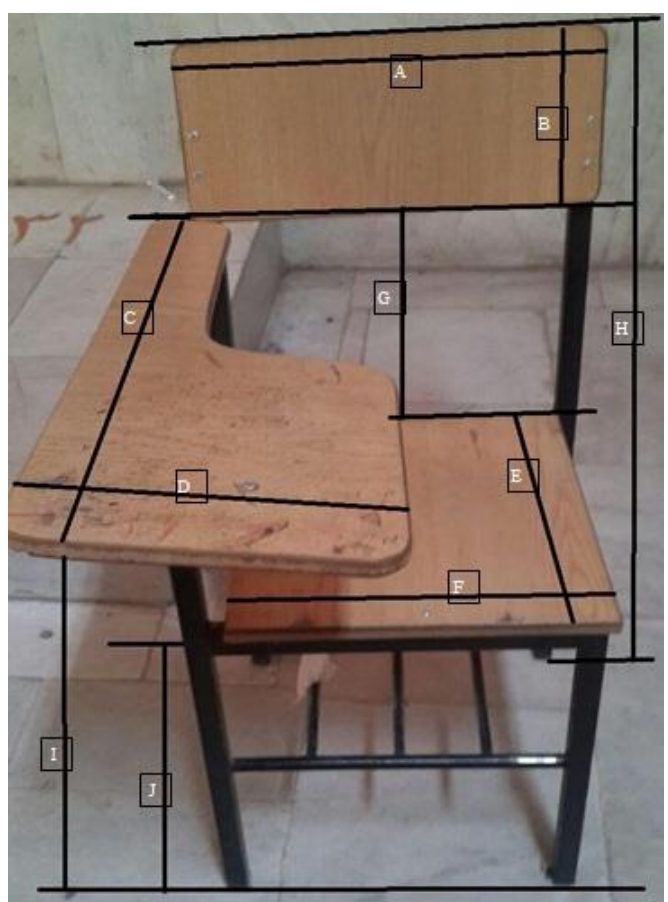

Figure 1: A: bench backrest width, B: bench backrest length, C: bench armrest length, D: bench armrest length, E: bench seat length, F: bench seat width, G: chair armrest to seat height, H: chair height, I: bench armrest height, J: bench seat to ground height (31)

\section{Results}

The rate of participation in study of students who studied in the four faculties of humanities, nursing-midwifery, agriculture, and engineering at undergraduate level was $6.7 \%$. Tables 1 and 2 present demographic characteristics, and classification of the students based on their BMI, respectively.

Table 1: Demographic characteristics of the students

\begin{tabular}{llc}
\hline Variable & Mean & Standard deviation \\
\hline Age $($ year $)$ & 27.12 & 8.01 \\
\hline Height $(\mathrm{cm})$ & 159.53 & 5.52 \\
\hline Weight $(\mathrm{kg})$ & 60.50 & 10.23 \\
\hline
\end{tabular}

According to table 2, 50\% of the subjects had normal weight status and $33 \%$ were overweight to various degrees. Four chair models (A, B, C, D) with different dimensions were used at the above-mentioned faculties and statistical tests showed no significant differences between dimensions of chairs. 
Table 2: Classification of students based on body mass index

\begin{tabular}{lcc}
\hline Variable & Number & Percent \\
\hline Weight loss & 18 & 17.8 \\
\hline Normal weight & 50 & 49.5 \\
\hline Over weight & 27 & 26.7 \\
\hline First class obesity & 3 & 3.0 \\
\hline Second class obesity & 3 & 3.0 \\
\hline Total & 101 & 100 \\
\hline
\end{tabular}

Therefore, mean chair dimensions presented in table 3 were used in order to investigate the relationship between postural abnormalities (kyphosis and lordosis) and chair dimensions.
Lordosis was the only significant abnormality among the students based on various dimensions of chairs.

Table 3: Mean ergonomic size of chairs in universities

\begin{tabular}{lcc}
\hline Variable & Mean & Standard deviation \\
\hline Bench seat length $(\mathrm{cm})$ & 39.48 & 0.66 \\
\hline Bench seat width $(\mathrm{cm})$ & 39.79 & 1.16 \\
\hline Bench backrest height $(\mathrm{cm})$ & 17.53 & 4.99 \\
\hline Bench armrest to ground height $(\mathrm{cm})$ & 69.82 & 1.45 \\
\hline Bench armrest length $(\mathrm{cm})$ & 50.46 & 5.44 \\
\hline Chair height $(\mathrm{cm})$ & 84.07 & 1.17 \\
\hline Bench seat to ground height $(\mathrm{cm})$ & 41.55 & 0.59 \\
\hline Chair back and seat angle $($ degree $)$ & 94.60 & 12.07 \\
\hline Chair armrest to seat height $(\mathrm{cm})$ & 23.76 & 2.26
\end{tabular}

Table 4 shows the frequency (number and percent) of these abnormalities in cases like backrest height, seat to ground height, armrest height, and armrest to seat height.

Table 4: Different dimensions of available chairs in colleges and presence of lordosis postural abnormalities

\begin{tabular}{|c|c|c|c|c|c|c|}
\hline \multicolumn{3}{|c|}{ Chair name } & $\mathrm{D}$ & $\mathrm{C}$ & B & A \\
\hline \multicolumn{3}{|c|}{ Backrest height } & 24 & 21.50 & 18.50 & 11.50 \\
\hline \multirow{4}{*}{ lordosis } & \multirow{2}{*}{ Yes } & Number & 4 & $\overline{9}$ & $\overline{1}$ & 14 \\
\hline & & Percent & 66.7 & 18 & 20.0 & 35.9 \\
\hline & \multirow{2}{*}{ No } & Number & 2 & 41 & 4 & 25 \\
\hline & & Percent & 33.3 & 82 & 80 & 64.1 \\
\hline \multicolumn{3}{|c|}{ Chair name } & $\bar{D}$ & $\mathrm{C}$ & $\mathrm{B}$ & $\mathrm{A}$ \\
\hline \multicolumn{3}{|c|}{ Seat to ground height } & 39.5 & 41.50 & 41.00 & 42 \\
\hline \multirow{4}{*}{ lordosis } & \multirow{2}{*}{ Yes } & Number & 4 & $\overline{9}$ & $\overline{1}$ & $\overline{14}$ \\
\hline & & Percent & 66.7 & 18 & 20 & 35.9 \\
\hline & \multirow{2}{*}{ No } & Number & 2 & 41 & 4 & 25 \\
\hline & & Percent & 33.3 & 82 & 80 & 64.1 \\
\hline \multicolumn{3}{|c|}{ Chair name } & $\overline{\mathrm{D}}$ & $\bar{C}$ & $\overline{\mathrm{B}}$ & $\overline{\mathrm{A}}$ \\
\hline \multicolumn{3}{|c|}{ Chair armrest height } & 50 & 68.5 & 73.5 & 71 \\
\hline \multirow{4}{*}{ lordosis } & \multirow{2}{*}{ Yes } & Number & 4 & 9 & 1 & 14 \\
\hline & & Percent & 66.7 & 18 & 20 & 35.9 \\
\hline & \multirow{2}{*}{ No } & Number & 2 & 41 & 4 & 25 \\
\hline & & Percent & 33.3 & 82 & 80 & 64.1 \\
\hline & air na & & $\bar{D}$ & $\bar{C}$ & $\bar{B}$ & $\mathrm{~A}$ \\
\hline \multicolumn{3}{|c|}{ Chair armrest to seat height } & 25.5 & 21.5 & 26.5 & 26 \\
\hline \multirow{4}{*}{ lordosis } & \multirow{2}{*}{ Yes } & Number & 4 & 1 & 1 & 14 \\
\hline & & Percent & 66.4 & 20 & 20 & 35.9 \\
\hline & \multirow{2}{*}{ No } & Number & 2 & 4 & 4 & 25 \\
\hline & & Percent & 33.3 & 80 & 80 & 64.1 \\
\hline
\end{tabular}

The surveys showed that 75 subjects $(74.3 \%)$ and 28 subjects $(27.7 \%)$, respectively, suffered from lordosis and kyphosis. There was a significant relationship between lordosis 
abnormality and height of backrest $(\mathrm{P}=0.04)$, seat to ground height $(\mathrm{P}=0.04)$, height of armrest $(\mathrm{P}=0.04)$, armrest to seat height $(\mathrm{P}=$ $0.04)$, and seat width $(\mathrm{P}=0.02)$. There was no significant relationship between kyphosis abnormality and ergonomic dimensions of chairs.

\section{Discussion}

The results showed incompatibility between physical dimensions of female students and dimensions of available chairs at the university, and that this incompatibility leads to some musculoskeletal abnormalities. Experts believe that more than $80 \%$ of Iranian female students suffer from musculoskeletal abnormalities due to poor movement and each Iranian student suffers from one or two problems related to stature structure including lordosis, drooping shoulder, parenthesisshaped legs, and abnormal curvature of the spine at high school $(22,32)$. These are not new statistics and their importance is revealed when we know that most of these disorders are associated with the education and school environment. This problem does not end with the ending of school and the erorrs in seating structures persist at universities (33). Failure to comply with standards of seating, where students spend most of their time, plays an undeniable role in disorders. There is little knowledge of individuals' dimensions in order to equip universities and provide academic requirements. Thus, individuals are required to make themselves compatible with the dimensions of equipment through changes in their body shape and structure. Many studies conducted on students indicate that improper dimensions of desks and chairs for students lead to postural disorders $(21,34,35)$. The results of researches on employees and other workers regarding ergonomics have indicated that failure to observe desk and chair ergonomics results in the occurrence of postural abnormalities $(36,37)$. The results showed that kyphosis was not related to any chair ergonomic dimensions in different faculties of Islamic Azad University, Ahvaz Branch. This finding is consistent with the findings of Sepehri et al. (38), but is not consistent with the findings of Zakeri et al. (36), Tavazo (37) Yousefi et al. (22), and Hanynn and Kosklo (8). Zakeri et al. reported a significant relationship between the variable of non-standard desks and chairs and prevalence of drooping shoulders, scoliosis, lordosis, and kyphosis disorders among 383 primary school students (36). In this study, based on standard seating dimensions, about $56.1 \%$ of the desks and chairs were nonstandard. Therefore, this difference in findings may be related to the high number of nonstandard tables and chairs (36). Tavazo studied 576 workers of the Oil and Gas Company (37). The results showed a significant positive relationship between dimension of desks and scoliosis and kyphosis. The participants of this study were male workers with different physical activities that may affect body posture differently and this may be the cause of differences with the female students (37). The participants of the study by Yousefi et al. included male students and the abnormality was observed in individuals whose body size did not fit the desks dimensions (22). They did not observe any significant relationship between kyphosis and incompatibility of chair with physical dimension (22). These results were in agreement with our findings. Hanynn and Kosklo found that students suffer from kyphosis disorder due to use of unsuitable chairs, but there was no statistics relationship with chair dimensions (8). Comparison of nonadjustable and adjustable chairs showed that adjustable chairs reduce kyphosis angle significantly after 12 months of intervention (8). The relationship between lordosis disorder and height of backrest, seat to ground height, and seat width was significant. This finding was consistent with findings of Zakeri et al. (36), Sepehri et al. (38), Barakat et al. (39), Tirgar et al. (40), Daneshmandi and Isa Nejad (41), Yousefi et al. (22), and Hanynn and Kosklo (8). It must be noted that many of the researches that examined the relationship 
between non-ergonomic chairs (nonadjustable) and pain in lumbar and cervical areas showed that using non-ergonomic chairs was related to pain in the mentioned areas $(8$, 42-45). This is consistent with the findings of the present study. Lordosis is inward curving of a part of the lumber vertebral column. Excessive lordosis is termed swayback or saddle back. Anterior pelvic tilt is a major causative factor of lordosis. Patients with lordosis often show a visible arch in their lower backs. There is evidence that many factors, such as age, gender, BMI, ethnicity, and sport, may affect the lordosis angle. The optimal lordotic range remains unknown and may be related to a variety of individual factors such as weight, activity, muscular strength, and flexibility of the spine and lower extremities (46). According to research findings regarding inappropriate height of chairs, the upper body, head, neck, and the imaginary gravity line crossing through the center of the upper body must be kept upright during sitting because there is greater pressure on discs particularly on fourth and fifth vertebrates in the sitting mode compared to standing mode. In an individual who bends forward on the chair due to inappropriate height, the pressure on the front vertebrates reaches $50-100 \mathrm{~kg}$ and this can lead to other spinal abnormalities $(42,47)$. When the chair height is inappropriate, knees are bent 90 degrees, the angle between thighs and upper body becomes 90 degrees, and maximum weight is supported by the ischium bone hyperostosis. Moreover, part of the right angle between thighs and upper body is met through bending the hip joint and, when it reaches a 60 degree angle, it is stopped by the hamstring muscle strain and the movement is completed by a 30 degree backward pelvic rotation that leads to shortening of the hamstring muscles and increasing of kyphosis (48). Chair seat width may lead to kyphosis disorder in persons with endomorph body type (obese) if the width of the buttocks is not equal to seat width. Similar studies were found on other significant relationships between kyphosis disorder and armrest height or armrest to seat height. Although, the relationships were statistically significant, they may not cause disorder based on the results presented in table 4. The findings show that the chair back angle is incompatible with students' physical size; therefore, with increase in chair back angle, a larger proportion of body weight is supported by the backrest. Thus, tension force between the upper body and pelvis (inner pressure of disc) is reduced, and increasing the angle between the upper body and thigh leads to lordosis abnormalities. The horizontal component of tension force is increased which leads to the movement of the buttocks toward the front of the chair seat $(42,45)$. Noncompliance of the angel Rear seats with seat $\left(110^{\circ}\right.$ angel of trunks with thigh) in addition to increased muscle tension in the neck, shoulder, and arm can cause back pain, kyphosis, forward head, reduced pelvic angle, increased use of energy to maintain the upper body vertically, and discomfort (49).

Researches show that lack of proportionality between chair dimensions leads to early pains, and cervical, back, and lumbar disorders, and reduces efficiency, and leads to Condition disorders including forward head, scoliosis, lordosis, and kyphosis in the long-term (42, $43,50,51)$. The comparison of pain between workers who used adjustable ergonomic chairs and those who used non-ergonomic chairs during 12 months showed significant difference between the two groups (52). Given that students spend the majority of hours in their day sitting and in static forms, it is necessary to buy or build equipment based on ISO and UNESCO standards and design and distribute a variety of desk and chair sizes based on body size (53). Some minor changes can be applied in the design of chairs through embedding holes and thin metal rods, and they can be made compatible to students' body in order to achieve energy efficiency and prevent abnormalities and subsequent damages.

\section{Conclusion}


There is no written and accurate database on anthropometric dimensions of students and other groups such as workers, administrative staff, and etc. Therefore, it is suggested that similar studies be conducted regionally and in different branches of Islamic Azad University, as the largest academic organization in Iran. Furthermore, it is suggested that chairs compatible with students' dimensions are provided based on a database. These will, undoubtedly, increasing proportion of the student body will provide Concentration power, charisma and comfort him/ her studies on time.

\section{Acknowledgment}

The authors of this research wish to thank the deputy of Islamic Azad University, Ahvaz Branch, for their financial assistance and cooperation.

Conflict of interest: None declared.

\section{References}

1. Mohseni-Bandpei M, Fakhri M, AhmadShirvani M, Bagheri-Nesami M, Khalilian A. Risk factors for low back pain in nurses of Mazandaran province. Journal of Mazandaran University of Medical Sciences 2006; 15(50):118-24.

2. Alexopoulos EC, Stathi ICh, Charizani F. Prevalence of musculoskeletal disorders in dentist. BMC Musculoskelet Disord 2004; 5:16. doi:10.1186/1471-2474-5-16

3. Kathy Cheng HY, Cheng CY, Ju YY. Workrelated musculoskeletal disorders and ergonomic risk factors in early intervention educators. Appl Ergon 2013; 44(1):134-41.

4. Yu W, Yu IT, Wang X, Li Z, Wan S, Qiu H, et al. Effectiveness of participatory training for prevention of musculoskeletal disorders: a randomized controlled trial. Int Arch Occup Environ Health 2013; 86(4):431-40.

5. Saeidi M. Low back pain and neck pain in related to poor posture in Hospital female personnel of Fateme-Zahra Hospital, NajafAbad. Journal of Research in Rehabilitation Sciences 2011; 7(3):259-66.

6. Bot SDM, Terwee CB, van der Windt DAWM, van der Beek AJ, Bouter LM, Dekker J. Workrelated physical and psychosocial risk factors for sick leave in patients with neck or upper extremity complaints. Int Arch Occup Environ Health 2007; 80(8):733-41.

7. Werner RA, Franzblau A, Gell N, Hartigan AG, Ebersole M, Armstrong TJ. Risk factors for visiting, a medical department because of upper-extremity musculoskeletal disorders. Scand J Work Environ Health 2005; 31(2):1327.

8. Hänninen O, Koskelo R. Adjustable tables and chairs correct posture and lower muscle tension and pain in high school students. Paper Presented at: The 15th Triennial Congress of the International Ergonomics Association; 2003 August 24-29; Seoul, Korea.

9. Lorusso A, Bruno S, L'Abbaate N. A review of low back pain and musculoskeletal disorders among Italian nursing personnel. Ind Health 2007; 45(5):637-44.

10. Mohseni Bandpey MA, Fakhri M, Ahmad Shirvani M, Bagheri Nesami M, Khalilian A. Epidemiological aspects of low back pain in nurses. Journal of Babol University of Medical Sciences 2005; 7(2):35-40.

11. Harutunian K, Gargallo-Albiol J, Figueiredo R, Gay-Escoda C. Ergonomics and musculoskeletal, pain among postgraduate students and faculty members of the school of dentistry of the university of Barcelona (Spain). A crosssectiona study. Med Oral Patol Oral Cir Bucal 2011; 16(3):e425-9.

12. Dianat I, Karimi MA, Asl Hashemi A, Bahrampour S. Classroom furniture and anthropometric characteristics of Iranian high school students: Proposed dimensions based on anthropometric data. Appl Ergon 2013; 44(1):101-8

13. Yektaee T, Tabatabaee Ghomshe F, Piri L. The effect of ergonomic principles education on musculoskeletal disorders among computer users. Archives of Rehabilitation 2013; 13(4):108-16 .

14. Mirmohammadi SJ, Mehrparvar AH, Soleimani $\mathrm{H}$, Lotfi MH, Akbari $\mathrm{H}$, Heidari N. Musculoskeletal disorders among video display terminal (VDT) workers comparing with other office workers. Iran Occupational Health Journal 2010; 7(2):11-14.

15. Khosroabadi AA, Razavi SM, Fallahi M, Akaberi A. The prevalence of musculoskeletal disorders in health treatment employees at Sabzevar University of Medical Sciences, Iran in 2008. Journal of Sabzevar University of Medical Sciences 2010; 17(3): 218-23.

16. Alizadeh MH, Gharakhanlou R, Daneshmandi H. Corrective and therapeutic Exercises. $2^{\text {nd }}$ ed. 
Tehran, Iran: ACECR, Allameh Tabatabaei University Press; 2004

17. Sayari A, Farahani A, Ghanbarzadeh M. Study and comparison effect of structural corrective exercise and aerobic corrective exercise program on some pulmonary indices of kyphoyic students in Ahwaz Shahid Chamran University. Olympic 2006; 14(3):61-9.

18. Ghafori F, Havanloo F, Asghari A, Arshadi R. Relationship between kyphosis and depression and anxiety in athlete and non-athlete male students in Selected University of Tehran. Research on Sport Science 2006; 4(12):107-22.

19. Daneshmandi H, Alizadeh MH, Gharakhanlou R. Corrective Exercises. $1^{\text {st }}$ ed. Tehran, Iran: Samt Press; 2008.

20. Vuillerme N, Pinsault N, Vaillant J. Postural control during quit standing following cervical muscular - fatigue: effect of change in sensory input. Nneurosci Lett 2005; 378(3):135-9.

21. Magee DJ. Orthopedic physical assessment. $5^{\text {th }}$ ed. Philadelphia, United States: Saunders; 2007; P.873-5.

22. Yoosefy B. A study of the relationship among come ergonomic features of school desks \& benches and anthropometry indexes of male students from Kermanshah plus prevalence of spinal column and upper skeletal organ abnormalities. Harakat 2006; (26):23-40.

23. Mehrabani F, Mehrabani J. Evaluation of the level of physical activity, obesity, and musculoskeletal abnormalities in university students. Tabari Journal of Preventive Medicine 2016; 2(3):33-43.

24. Chobineh AR, Mouodi MA. The human, anthropometry, ergonomics, and design. $5^{\text {th }}$ ed. [S. Fyznt, Trans]. Tehran: Markaz Nashr Press; 2013.

25. Vafaee B, Zaree F, Nikpey A, Varmazyar S, Safaryvariani A. Review the proportion of university seats with body dimensions of students at the School of Public Health of Qazvin University of Medical Sciences in 1388. Iran Occupational Health Journal 2011; 8(3):39-47.

26. Klamklay J, Sungkhapong A, Yodpijit N, Patterson PE. Anthropometry of the Southern Thai population. Int J Ind Ergon 2008; 38(1):111-8.

27. Alnaser MZ, Wughalter EH. Effect of chair design on ratings of discomfort. Work 2009; 34(2):223-34.

28. Zamani BE, Nasr Esfahani AR. Physical and cultural characteristics of instructional spaces in four developed countries from the viewpoints of Iranian parents and students. Journal of Educational Innovations 2008; 6(23): 55-84.
29. Ming Z, Närhi M, Siivola J. Neck and shoulder pain related to computer use. Pathophysiology 2004; 11(1):51-6.

30. Sokhanguie Y, Afsharmand Z. Corretive Exercises. 1st ed. Tehran: Hatmi Press; 2013.

31. Ismaila SO, Musa AI, Adejuyigbe SB, Akinyemi OD. Anthropometric design of furniture for use in tertiary institutions in abeokuta, South-Western Nigeria. Engineering Review 2013; 33(3):179-92.

32. Fathi M, Rezaei R. The study and comparison of postural abnormalities in boy and girl middle school and high school students. Roshd in physical education 2010; 11(1):46-53.

33. Kargarfard M, Mahdavi-Nejad R, Ghasemi GhA, Rouzbehani R, Ghias M, Mahdavi-Jafari $\mathrm{Z}$, et al. Assessment of spinal curvature in Isfahan university students. Journal of Isfahan Medical School 2010; 27(102):762-76.

34. Irandoost KH. The relationship between lower limb deformities and spine with biometric body dimensions and tools used in school and life boys and girls 8 to 11 years in Qazvin [Research Project]. Qazvin: Qazvin University; 2004.

35. Rezvani Tarshizi A. Determination anthropometric characteristics of high schools students Tehran to design desks and benches [MSc thesis]. Tehran: Tarbiat Modares University; 1996.

36. Zakeri Y, Gheibizadeh M, Baraz SH, Bijan Nejad D, Latifi SM. Relationship between features of desks and prevalence of skeletal disorders in primary school students in Abadan. Int J Pediatr 2016; 4(11):3949-56.

37. Tavazoa A. The examination of ergonomic relationship for occupational chair and desk with some of the abnormality in the upper limbs of inactive men and middle age personnel in N.I.S.O.C [MSc thesis]. Ahvaz: Shahid Chamran University; 2009.

38. Sepehri S, Habibi AH, Shakerian S. The relationship between ergonomic chair and musculoskeletal disorders in north of Khuzestan's students. Eur J Exp Biol 2013; 3(4):181-7.

39. Barakat S, Javan M, Dehghan H, Habibi E. Ergonomic assessment of body posture during work using the Rapid Entire Body Assessment method and prevalence of musculoskeletal disorders in dental students. Journal of Isfahan Dental School 2013; 9(5):423-32.

40. Tirgar A, Aghala Z, Salari F. Musculoskeletal disorders and awareness of ergonomic considerations in computer use among medical sciences students. Journal of Ergonomics 2014; 1(3):55-64. 
41. Daneshmandi H, Isanezhad A, Hematinezhad MA. The effects of classroom furniture on back, neck, lumbar and leg fatigue in student. Journal of movement science \& sports 2008; 5(1 Special Issue):37-44.

42. Kendall FP, McCreary EK, Provance PG, Rodgers MM, Romani WA. Muscles: testing and function with posture and pain. $5^{\text {th }} \mathrm{ed}$. Philadelphia, United States: Lippincott Williams \& Wilkins; 2005.

43. Murphy S, Buckle P, Stubbs D. A crosssectional study of self-reported back and neck pain among English schoolchildren and associated physical and psychological risk factors. Appl Ergon 2007; 38(6):797-804.

44. Trevelyan FC, Legg SJ. Risk factors associated with back pain in New Zealand school children. Ergonomics 2011; 54(3):257-62.

45. Pheasant S. Human, anthropometry, ergonomics and design. [AR. Choobineh, MA Mouoodi Trans]. 5th ed. Tehran: nashr-emarkaz; 2016.

46. Been E, Kalichman L. Lumbar lordosis. The Spine Journal 2014; 14(1):87-97.

47. Mandal ÅC. Work-chair with tilting seat. Ergonomics 1976; 19(2):157-64.

48. Bridger RS, Von Eisenhart-Rothe C, Henneberg M. Effects of seat slope and hip flexion on spinal angles in sitting. Hum Factors 1989; 31(6):679-88.

49. Sanders MS, McCormick EJ. Ergonomics (human factors in design engineering) [MR. Afzali Trans]. 7th ed. Tehran: University Sciences Press; 1999.

50. Panagiotopoulou G, Christoulas K, Papanckolaou A, Mandroukas K. Classroom furniture dimensions and anthropometric measures in primary school. Appl Ergon 2004; 35(2):121-8

51. Knight G, Noyes J. Children's behavior and the design of school furniture. Ergonomic 1999; 42(5):747-60.

52. Amick BC 3rd, Robertson MM, DeRango K, Bazzani L, Moore A, Rooney T, Harrist R. Effect of office ergonomics intervention on reducing musculoskeletal symptoms. Spine 2003; 28(24):2706-11.

53. Switzerland, International Organization for Standardization. ISO 5970:1979. Furniture Chairs and tables for educational institutions Functional sizes. Geneva 2012. Report No.: TC/SC: ISO/TC 136, ICS: 97.140. Available from:

http://www.iso.org/iso/home/store/catalogue_tc /catalogue_detail.htm?csnumber=12165. 